\title{
Adesivo biológico de fibrina na mioescleropexia posterior em coelhos - Estudo experimental
}

\author{
Fibrin biological adhesive for posterior mioscleral fixation of superior rectus muscles - \\ An experimental study in rabbits
}

\author{
Ana Tereza Ramos Moreira ${ }^{1}$ \\ Juliana Mantovani Bottós ${ }^{2}$ \\ Kátia Mantovani Bottós ${ }^{3}$ \\ Michele Buquera ${ }^{4}$ \\ Adilson dos Anjos 5
}

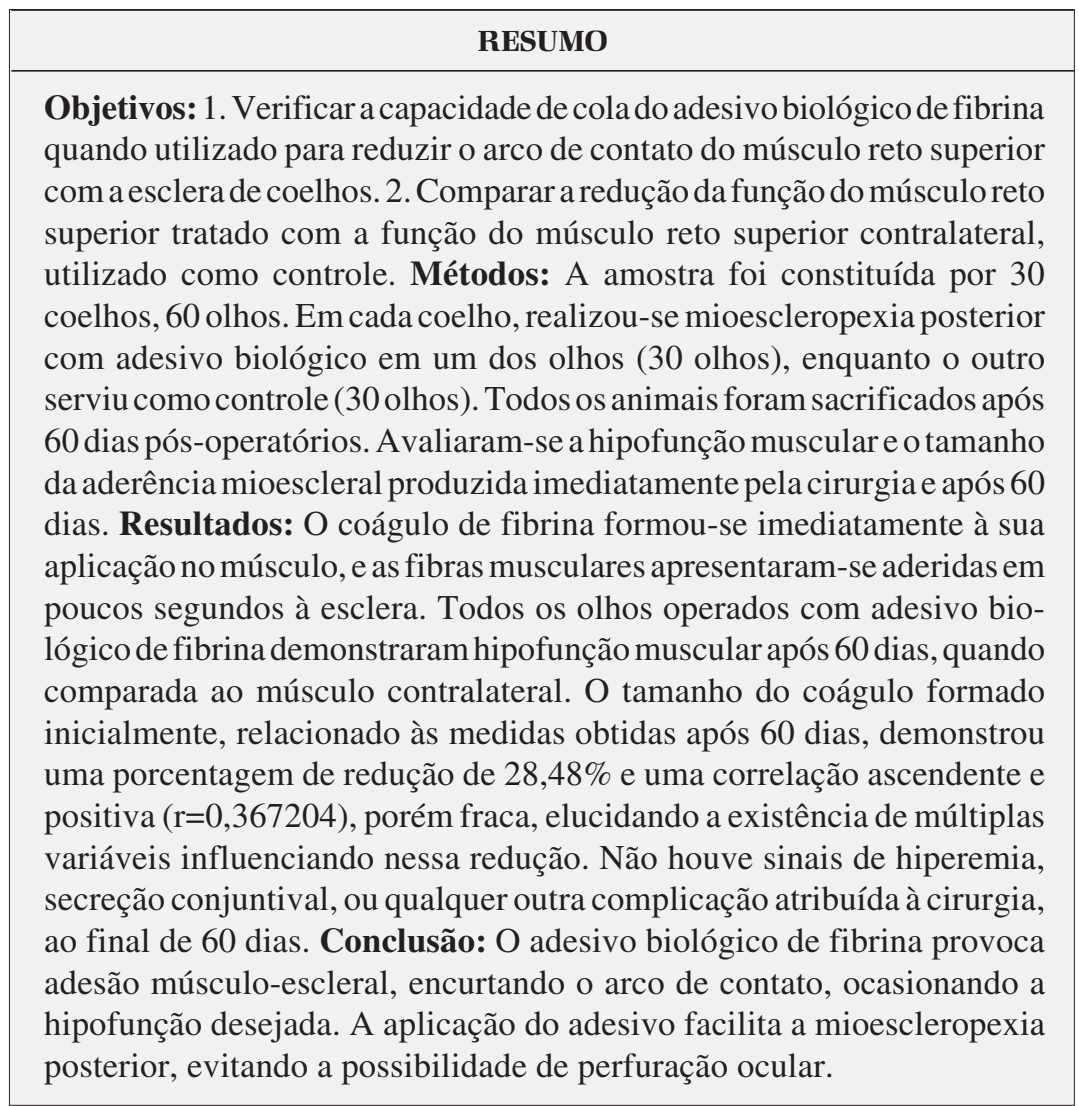

Descritores: Adesivo tecidual de fibrina; Músculos oculomotores/cirurgia; Técnicas de sutura; Animal; Coelhos/cirurgia

CNPq.

3 Acadêmica do décimo período de Medicina da Universidade Federal do Paraná - UFPR.

${ }^{4}$ Médica Oftalmologista do Hospital de Olhos do Paraná.

${ }^{5}$ Estatístico chefe do laboratório de estatística da Universidade Federal do Paraná - UFPR.

Endereço para correspondência: Ana Tereza Ramos Moreira - Rua Fernando Simas, 1010 - Curitiba (PR) CEP 80430-190

E-mail: anatemoreira@hotmail.com

Recebido para publicação em 31.03.2003

Versão revisada recebida em 31.10 .2003

Aprovação em 18.11.2003

Nota Editorial: Pela análise deste trabalho e por sua anuência na divulgação desta nota, agradecemos ao Dr. Renato Luiz Nahoum Curi.

\begin{abstract}
INTRODUÇÃ̃O
A busca da melhor técnica cirúrgica, assim como o melhor material de sutura a ser utilizado nas cirurgias de estrabismo inspiraram vários modelos experimentais com lesões induzidas em tecido muscular extra-ocular ${ }^{(1-6)}$.

Algumas características dos fios sintéticos podem ser responsáveis pela grande preferência dos cirurgiões, como, por exemplo, a maior força de tensão durante a fase de cicatrização e a maior rapidez de absorção uniforme. Por conseguinte, a menor reação inflamatória pós-operatória, decorrente da menor antigenicidade e, também, a facilidade e segurança relativa ao nó cirúrgico em relação aos fios de sutura utilizados anteriormente, explicam a maior utilização dos fios sintéticos ${ }^{(7-9)}$.
\end{abstract}


"Fadenoperation" ou mioescleropexia posterior foi inicialmente descrita por Cuppers, em 1974, e consiste em suturar o músculo extra-ocular à esclera posteriormente ao equador do globo ocular, reduzindo a ação do músculo operado através do encurtamento do arco de contato fisiológico, sem alteração do seu arco de contato anatômico, produzindo desta maneira uma paresia artificial. Atualmente essa técnica é indicada nos seguintes casos:

- Estrabismo incomitante que, em posição primária do olhar encontra-se em ortotropia;

- Divergência vertical dissociada;

- Nistagmo;

- $\quad$ Síndrome de Stilling-Türk-Duane tipo 1;

- e principalmente, como complemento ao recuo máximo numa cirurgia.

A difícil exposição do campo cirúrgico, com possível falha na técnica se a sutura for anteriorizada em relação ao plano inicial, e a possibilidade de perfuração do globo ocular, desestimularam muitos cirurgiões a adotarem esta técnica em sua rotina cirúrgica (International Strabismological Association Meeting, 1995), mas motivaram a pesquisa para o desenvolvimento de novas técnicas que pudessem substituir a sutura tradicional. Dentre tais pesquisas sobressai a síntese por adesivo biológico ${ }^{(10)}$.

Em cirurgia oftalmológica, o adesivo de fibrina, composto por fibrinogênio e trombina, foi utilizado pela primeira vez por Brown e Nantz, em $1944^{(11)}$ para fechamento de feridas em córneas de coelhos. A partir de então, o adesivo biológico tem sido muito usado em diversos procedimentos cirúrgicos oftalmológicos experimentais ou mesmo em seres humanos ${ }^{(12)}$.

$\mathrm{O}$ adesivo biológico de fibrinogênio e trombina, quando comparado a outros adesivos de cianoacrilato, apresenta a vantagem de ser totalmente absorvível ${ }^{(13)}$ além de ser considerado o melhor entre os adesivos teciduais ${ }^{(14)}$.

O fibrinogênio é o precursor direto da fibrina insolúvel, estrutura fundamental do coágulo sanguíneo. A trombina é uma enzima proteolítica que ativa o fibrinogênio, rompendo-o em dois fibrinopeptídios, A e B, formando, dessa maneira, o monômero de fibrina ${ }^{(15)}$. Através de ligações hidrogeniônicas ocorre a polimerização da molécula, formando o polímero de fibrina que é o coágulo ${ }^{(16)}$.

O coágulo formado ao final dessas etapas tem o poder de aderência às estruturas adjacentes semelhante aos adesivos químicos. A adição de antifibrinolíticos impede a fibrinólise rápida e estabiliza o adesivo até que este seja substituído por tecido conectivo ${ }^{(17)}$.

\section{OBJETIVOS}

1. Verificar a capacidade de adesão do adesivo biológico de fibrina quando utilizado para encurtar o arco de contato com a esclera, do músculo reto superior de coelhos.

2. Comparar a redução da função do músculo reto superior tratado, com a função do músculo reto superior contralateral usado como controle.

\section{MÉTODOS}

Para a realização deste trabalho, foram utilizados coelhos machos da raça Nova Zelândia, com peso variando entre 2 a $2,5 \mathrm{~kg}$, sem sinais de doença. Adotaram-se os critérios preconizados pela Association for Research in Vision and Ophthalmology (ARVO) como norma para o desenvolvimento deste projeto.

A amostra constou de 30 coelhos, 60 olhos, sendo um olho de cada coelho destinado à aplicação do adesivo (30 olhos), enquanto o outro olho foi utilizado como controle (30 olhos). Todos os coelhos foram operados e sacrificados após 60 dias pós-operatórios.

A preparação dos componentes do adesivo consistiu em várias etapas seguidas criteriosamente quanto à temperatura $\mathrm{e}$ tempo de aquecimento. Um concentrado de proteínas para fins adesivos: basicamente fibrinogênio e trombina, constitui o adesivo utilizado neste trabalho.

O fibrinogênio é reconstituído com uma solução de aprotinina bovina, um inibidor natural da protease, para que haja absorção gradual do adesivo biológico pelo organismo, com tempo suficiente para a formação de tecido conectivo.

O segundo componente do adesivo biológico de fibrina é a trombina humana, reconstituída com solução de cloreto de cálcio removido previamente da solução. Isso foi feito para evitar a coagulação durante a coleta do sangue. Na presença de cálcio, a trombina ativa o fator XIII da coagulação sanguínea, que catalizará ligações cruzadas entre o grupo amino de uma molécula e o grupo carbonil de outra, formando ligações peptídicas que estabilizarão o coágulo. A mistura do fibrinogênio com a trombina produz o coágulo, adesivo, resultado da polimerização da fibrina, capaz de aderir tecidos em atos cirúrgicos.

Os dois componentes elaborados previamente foram misturados, em partes iguais utilizando seringas especiais (Duploject $\left.{ }^{\circledR}\right)$, no momento da cirurgia.

Todas as cirurgias foram realizadas pela mesma equipe para evitar alterações no procedimento e técnica cirúrgica.

Com os animais anestesiados, realizou-se a incisão conjuntival de 11 horas a 2 horas, via fórnix. Seccionaram-se os ligamentos intermusculares e as demais conexões entre a cápsula muscular e a cápsula de Tenon, com dissecção ampla do músculo reto superior até aproximadamente $14 \mathrm{~mm}$ do limbo. Isolou-se o tendão do músculo oblíquo superior, que foi desinserido e nele feita uma miectomia ampla, permitindo que o músculo se afastasse da inserção e não interferisse com a adesão do músculo reto superior à esclera. Nos coelhos, o tendão do músculo oblíquo superior encontra-se inserido atrás do reto superior, abaixo de sua cápsula e aderido a ela.

Com dois ganchos de estrabismo, as inserções anatômicas do músculo reto superior foram erguidas. Com o auxílio de duas seringas de insulina, uma contendo a solução de fibrinogênio e a outra a solução de trombina, injetaram-se simultaneamente 0,1 a 0,2 $\mathrm{ml}$ de cada substância, em localização bem posterior, entre o corpo muscular e a esclera. Ambos os componentes do adesivo foram injetados em quantidades iguais, unidos entre si por um conector especial com via única. Realizou-se pressão sobre o músculo durante 1 minuto com o 
auxílio de um "cotonete". O coágulo formado foi medido com compasso oftalmológico. Recolocou-se a conjuntiva na posição primitiva, suturando-a com Vicryl ${ }^{\circledR} 6,0$.

O resultado cirúrgico foi comparado com o olho contralateral do mesmo animal, que não foi submetido a qualquer tratamento (grupo controle), no $60^{\circ}$ dia pós-operatório.

O exame clínico foi realizado a olho nu, por três observadores que desconheciam a técnica utilizada em cada olho. Para a pesquisa da função do músculo reto superior, os examinadores seguraram o coelho por suas patas anteriores, de modo que houvesse depressão da cabeça, ocorrendo assim a supraversão dos olhos, a fim de averiguar a função do músculo operado em seu campo de ação.

O tamanho da aderência músculo-escleral provocada pelo adesivo ao final de 60 dias foi medido e comparado com o tamanho do coágulo no momento da cirurgia.

Para o estudo estatístico das variáveis foram feitas análises descritivas quando estas eram suficientes para a tomada das decisões. Adotaram-se análises de correlação com nível de significância de $5 \%$.

\section{RESULTADOS}

Observou-se limitação da supraversão em todos os olhos tratados com adesivo biológico, comparados aos olhos controles.

A formação do coágulo de fibrina variou entre o imediato contato do fibrinogênio com a trombina até 25 segundos após a mistura das duas substâncias. Após esse tempo, todas as fibras musculares apresentaram-se aderidas à esclera.

Nenhum olho apresentou secreção conjuntival no $2^{\circ}$ dia pós-operatório. A hiperemia conjuntival esteve presente em 7 dos 30 olhos tratados com adesivo. Ao $7^{\circ}$ dia pós-operatório já não se observava hiperemia ou secreção conjuntival nos olhos operados.

Durante a enucleação, observou-se aderência músculoescleral no local exato da aplicação do adesivo biológico, constatado em todos os olhos operados. A tabela 1 mostra a relação entre o tamanho do coágulo formado no momento da cirurgia e após o $60^{\circ}$ dia pós-operatório.

As figuras 1,2 e 3 mostram a aderência mio-escleral no $60^{\circ}$ dia pós-operatório.

A tabela 2 relaciona as médias, variâncias, desvio padrão e valores máximo e mínimo referentes aos tamanhos das aderências no ato cirúrgico e após 60 dias da operação.

\section{DISCUSSÃO}

A preparação do adesivo biológico mostrou-se dificultada pelo minucioso processo de reconstituição dos componentes do adesivo, com temperaturas e tempo de preparo precisos, comprometendo a viabilidade do processo e integridade do material. Além disso, o adesivo biológico apresenta um custo elevado, dificultando também o seu emprego freqüente em estudos experimentais ${ }^{(18)}$.

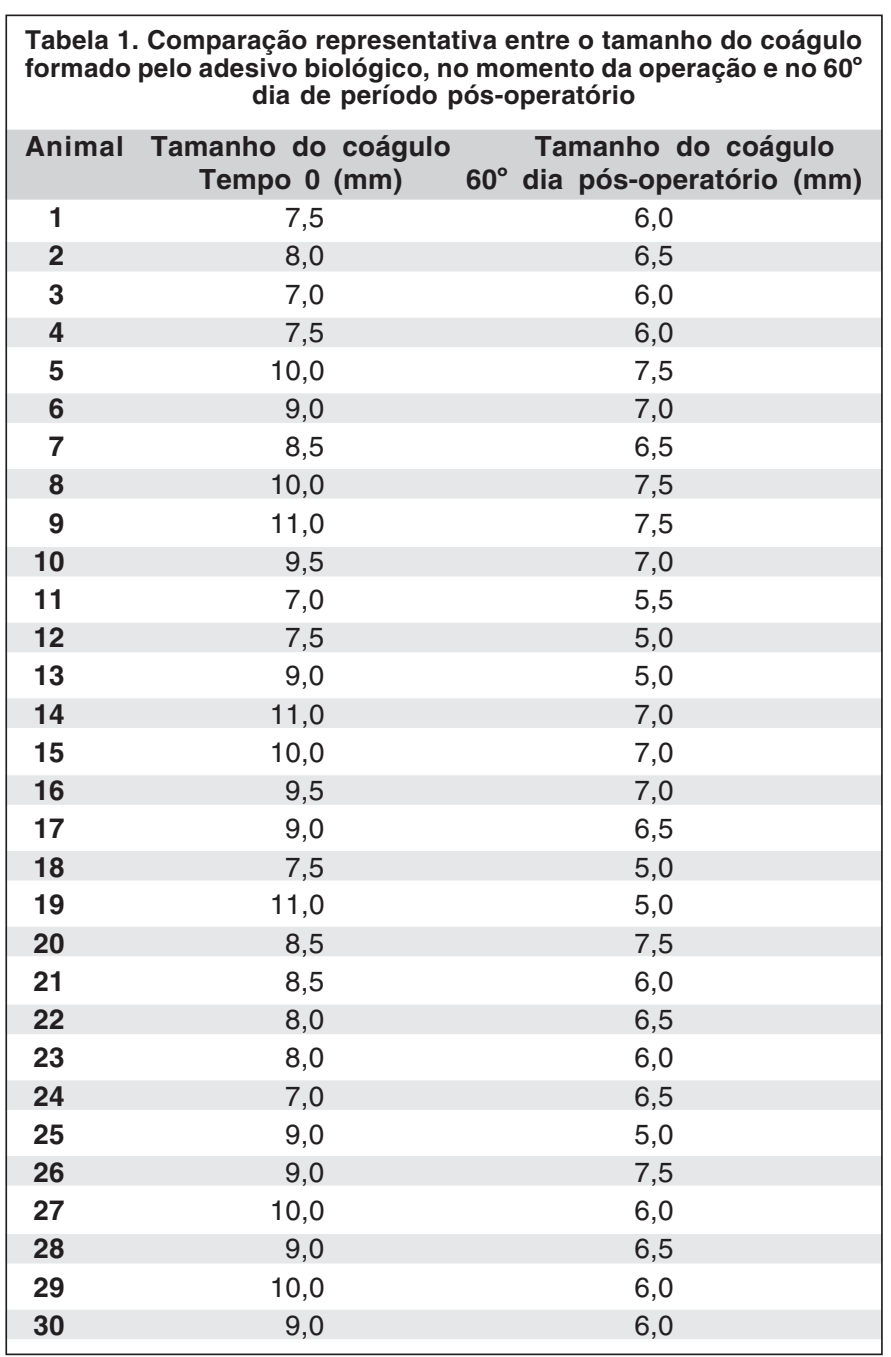

Observou-se que alguns coágulos se formavam mais rapidamente do que outros. Nos coágulos formados mais lentamente, a concentração de trombina era menor que a de fibrinogênio, o inverso ocorrendo com os formados mais rapidamente. Sabe-se que a velocidade de transformação do fibrinogênio em fibrina e conseqüente formação do coágulo depende em grande parte da concentração de trombina, podendo variar de imediata até 30 segundos ${ }^{(16)}$.

Após a preparação adequada do fibrinogênio e da trombina, as duas substâncias foram utilizadas nas cirurgias, com intervalo que variou entre o degelo e no máximo três horas. Foi observada maior instabilidade do coágulo nos coelhos nos quais as substâncias aplicadas permaneceram maior tempo em degelo. Atribuímos a este fato a alteração, pela temperatura ambiente, das ligações hidrogeniônicas que ocorrem na formação do polímero de fibrina, tornando o coágulo mais instável. Dresdale et al. em 1985, constataram a alteração das propriedades do fibrinogênio quando exposto à temperatura ambiente por mais de 4 horas $^{(19)}$.

Outra propriedade do adesivo de fibrina observada durante a cirurgia foi a sua capacidade hemostática. Em uma das 


\begin{tabular}{|c|c|c|}
\hline & $\begin{array}{l}\text { Momento da } \\
\text { operação }\end{array}$ & $\begin{array}{c}60^{\circ} \text { dia } \\
\text { pós-operatório }\end{array}$ \\
\hline Média & $8,85 \mathrm{~mm}$ & 6,33333 mm \\
\hline Variância & 1,43362 & 0,678161 \\
\hline Desvio padrão & 1,19734 & 0,823505 \\
\hline Valor mínimo & $7,0 \mathrm{~mm}$ & $5,0 \mathrm{~mm}$ \\
\hline Valor máximo & $11,0 \mathrm{~mm}$ & $7,5 \mathrm{~mm}$ \\
\hline Intervalo & 4,0 & 2,5 \\
\hline
\end{tabular}

cirurgias, houve rompimento de um vaso durante a incisão conjuntival, causando hemorragia. Após a aplicação do adesivo biológico, a hemostasia foi imediata.

Quando se administram produtos medicinais a partir de sangue humano, não se pode excluir totalmente a possibilidade de contágio por doenças infecciosas. Em vista disso, os doadores são selecionados segundo critérios rígidos, o plasma doado é testado e selecionado e os bancos de plasma são controlados, incluindo procedimentos para remoção e inativação de vírus, entre os quais os vírus da hepatite $\mathrm{B}$ e da síndrome da imunodeficiência adquirida (AIDS) ${ }^{(20)}$ Todos os doadores aptos são, obrigatoriamente, sorologicamente negativos.

O coeficiente de correlação $(r)=0,367204(p<0,05)$ traduz uma relação positiva, ascendente, entre o tamanho do coágulo formado no momento da sua aplicação e o tamanho da área de aderência músculo-escleral obtido após 60 dias. Essa relação, no entanto, é baixa. O desvio padrão das áreas de aderência formadas no $60^{\circ}$ dia pós-operatório foi mínimo $(0,823505 \mathrm{~mm})$, permanecendo dentro de valores estreitos (entre 5 e $7,5 \mathrm{~mm}$ ) com intensidade pequena de correlação ao tamanho do coágulo inicialmente formado. Julgou-se, portanto, que outras fontes de variação influenciariam no comportamento das aderências observadas após 60 dias. Acredita-se que, dentre tais variáveis, além do próprio tamanho do coágulo formado no ato cirúrgico, encontram-se: a concentração de trombina, o tempo de exposição do adesivo biológico à temperatura ambiente, a absorção fisiológica do adesivo biológico e, sobretudo, a própria curvatura do globo ocular, dificultando a adesão músculo-escleral a partir de um determinado valor $(>7,5 \mathrm{~mm})$. Novas pesquisas poderiam ajudar a elucidar outros fatores influentes.

A porcentagem de redução da área de aderência, relacionada ao tamanho do coágulo formado inicialmente, correspondeu a $28,48 \%$.

Não houve sinais de hiperemia, reação inflamatória ou secreção conjuntival nos olhos operados, ou qualquer outra complicação atribuída à cirurgia, ao final de 60 dias.

O exame clínico pós-operatório revelou uma limitação da elevação do olho operado. Atribuímos esse fato à adesão mais ampla do músculo à esclera produzida pelo adesivo biológico, encurtando desta forma o arco de contato do músculo com o bulbo ocular, e conseqüente redução da motilidade ocular pósoperatória. Todos os coelhos apresentaram limitação da supraversão quando comparada a do olho controle contralateral.

\section{CONCLUSÕES}

O adesivo biológico de fibrina provoca adesão do músculo reto superior à esclera ocular, encurtando o arco de contato, ocasionando a limitação da supraversão desejada. Desta forma, ele facilita a mioescleropexia posterior, evitando a possibilidade de perfuração ocular.

\section{ABSTRACT}

Purposes: 1. To evaluate the adhesion capacity of the fibrin biological adhesive in surgery of posterior fixation of the superior rectus muscle, when it is used for the reduction of the arc of contact. 2. To compare the reduction of the superior rectus muscle's action of eyes in which the biological adhesive has been used with those used as a control group. Methods: The sample consisted of 30 animals, 60 eyes. One of the eyes of each animal was treated with biological adhesive (30 eyes), while the other was used as a control (30 eyes). All animals were sacrificed on the $60^{\text {th }}$ postoperative day. Muscle reduction was analyzed and the sizes of the adherences produced at surgery and after 60 days were measured. Results: The fibrin clot was produced immediately after applying the biological adhesive and at the end of few seconds all muscle fibers were adhered to the sclera. All muscles treated with biological adhesive showed reduction in motor function on the $60^{\text {th }}$ postoperative day when compared with the control group. The sizes of the initially produced adherence compared with those after 60 days was reduced $28.48 \%$. There was an ascending and positive but weak correlation ( $\mathrm{r}=0.367204)$. There must exist other variables affecting adherence reduction. There was no significant inflammatory reaction or any other complication related to the surgery. Conclusions: The clinical results of motor function demonstrated that the biological adhesive of fibrin produced musclescleral adhesion, reducing the arc of contact of the superior rectus muscle in rabbits.

Keywords: Fibrin tissue adhesive; Oculomotor muscles/surgery; Suture techniques; Animal; Rabbits/surgery

\section{REFERÊNCIAS}

1. Ingram RM. Wound healing after operations on the extra-ocular muscles of monkeys. Br J Ophthalmol 1966;50:186-208.

2. Dunlap EA, Dunn M, Rossomondo R. Adhesives for sutureless muscle surgery. Arch Opthalmol 1969;82:751-5.

3. Salthouse TN, Matlaga BF, Wykoff MH. Comparative tissue response to six suture materials in rabbit cornea, sclera, and ocular muscle. Am J Ophthalmol 1977;84:224-33.

4. Estes RL, Sugar A. Knot integrity of coated synthetic absorbable sutures used for extraocular muscle surgery in a rabbit model. J Pediatr Ophthalmol Strabismus 1982;19:25-7.

5. Aichmair MW, Aichamair H, Lintner F. Fibrin gluing of the extraocular eye muscles. Experimental use in rabbit. Klin Montsbl Augenheilkd 1988;193: 499-503.

6. Ferreira RC, Lamberts M, Campos MSQ, Moreira BC. Hialuronato de sódio e hidroxipropilmetilcelulose na cirurgia ajustável de estrabismo. Arq Bras Oftalmol 1994;57:237-9. [Trabalho apresentado no $11^{\circ}$ Congresso Brasileiro de Prevenção da Cegueira e Reabilitação Visual; 1994 Set 3-6;Brasília]. 
7. Blaydes JE. New refinements in synthetic absorbable sutures and their application in ophthalmology. Trans Am Acad Ophthalmol Otolaryngol 1977;83: 297-301.

8. White RH, Parks MM. Polyglicolic acid sutures in ophthalmic surgery. Trans Am Acad Ophthalmol Otolaryngol 1974;78:OP632-6.

9. François J, Verbraeken H. Polyglycolic acid sutures in cataract and extraocular muscle surgery. Ophthalmologica 1978;176:102-4.

10. Rezende F. Cirurgia do estrabismo. In: Dias FR, editor. Controvérsias e complicações em cirurgia ocular. Rio de Janeiro: Cultura Médica; 1996. p.103-4.

11. Brown AL, Nantz FA - Corneal healing. Adhesive power of aqueous fibrin in the rabbit: preliminary report. Am J Ophthalmol 1944;27:1220-4.

12. Moreira ATR, Torres LFB, Scarpi MJ, Moreira Júnior CA, Miranda SP, Matsumoto LH. Uso do adesivo biológico de fibrina para reinserção de músculos retos superiores em coelhos. I- estudo clínico. Rev Bras Oftalmol 1998; 57:501-12.

13. Siedentop KH, Harris DM, Loewy A. Experimental use of fibrin tissue adhesive in middle ear surgery. Laryngoscope 1983;93:1310-3.
14. Fugmann EA. Viabilização do preparo e da aplicação do adesivo de fibrina. [Tese]. Curitiba: Universidade Federal do Paraná; 1993.

15. Cairutas CM. Frações concentradas de fatores hemostáticos. In: Cairutas CM. Componentes e derivados do sangue para uso terapêutico. Recife: Editora Universitária UFPE; 1985. p.177-232.

16. Brittain GP, Roston CK, Morton DB, Rees JE. The use of a biological adhesive to achieve sutureless epikeratophakia. Eye 1989;3:56-63.

17. Scheele J, Gentsch HH, Matteson E. Splenic repair by fibrin tissue adhesive and collagen fleece. Surgery 1984;95:6-13.

18. Bonatti JA, Stefano JT, Matheus LCA, Oliveira GA, Suzuki H, Kara-José N. Desenvolvimento de adesivo tecidual fibrínico para uso experimental em perfurações corneanas. Arq Bras Oftalmol 1995;58:354-6.

19. Dresdale A, Rose EA, Jeevanandam V, Reemtsma K, Bowman FO, Malm JR. Preparation of fibrin glue from single-donor fresh-frozen plasma. Surgery 1985;97:750-5.

20. Felding P, Nilsson IM, Hansson BG, Biberfeld G. Absence of antibodies to LAV/HTLV-III in haemophiliacs treated with heat-treated factor VIII concentrate of american origin. Lancet 1985;2:832-3.

\section{ABO ELETRÔNICO}

\section{A versáo eletrônica dos Arquivos Brasileiros de Offalmologia com textos completos está disponível em:}

-ABO Arquivos Brasileiros de Oftalmologia http://www.abonet.com.br

- SciELO - Scientific Electronic Library Online http://www.scielo.org

- Free Medical Journals - http:/www.freemedicaljournals.com 